\title{
Three-dimensional growth: a developmental innovation that facilitated plant terrestrialization
}

\author{
Laura A. Moody ${ }^{1}$ \\ Received: 25 October 2019 / Accepted: 11 February 2020 / Published online: 24 February 2020 \\ (c) The Author(s) 2020
}

\begin{abstract}
One of the most transformative events in the history of life on earth was the transition of plants from water to land approximately 470 million years ago. Within the Charophyte green algae, the closest living relatives of land plants, body plans have evolved from those that comprise simple unicells to those that are morphologically complex, large and multicellular. The Charophytes developed these broad ranging body plans by exploiting a range of one-dimensional and two-dimensional growth strategies to produce filaments, mats and branches. When plants were confronted with harsh conditions on land, they were required to make significant changes to the way they shaped their body plans. One of the fundamental developmental transitions that occurred was the evolution of three-dimensional growth and the acquisition of apical cells with three or more cutting faces. Plants subsequently developed a range of morphological adaptations (e.g. vasculature, roots, flowers, seeds) that enabled them to colonise progressively drier environments. 3D apical growth also evolved convergently in the brown algae, completely independently of the green lineage. This review summarises the evolving developmental complexities observed in the early divergent Charophytes all the way through to the earliest conquerors of land, and investigates 3D apical growth in the brown algae.
\end{abstract}

Keywords Apical growth $\cdot$ Brown algae $\cdot$ Charophyte $\cdot$ Development $\cdot$ Evolution $\cdot$ Land plant $\cdot$ Three-dimensional

\section{Introduction}

One of the most transformative events in the history of life on earth was the emergence of terrestrial plant life approximately 470 million years ago (Delwiche and Cooper 2015; Kenrick and Crane 1997). Before this time, photosynthesis only occurred in aquatic environments. Plants evolved a range of molecular, biochemical and morphological adaptations to enable them to survive and reproduce on land (Minami et al. 2003; Stevenson et al. 2016; Wolf et al. 2010). These included roots for anchorage and the acquisition of water and nutrients, leaves for capturing sunlight, vascular tissues for transport and mechanical support, and seeds and flowers for enhanced reproductive success. One of the most important innovations that enabled the assembly

Laura A. Moody

laura.moody@plants.ox.ac.uk

1 Department of Plant Sciences, University of Oxford, South Parks Road, Oxford OX1 3RB, UK of these morphological traits, was the evolution of threedimensional (3D) growth. 3D growth is an invariable and pivotal feature of all land plants, and the diverse sizes and morphologies exhibited across the terrestrial biosphere are all due to differential regulation of 3D growth processes during development. Interestingly, 3D growth is also exhibited within species of brown algae, and thus evolved completely independently of the green lineage in the water.

\section{The streptophytes}

The Viridiplantae ('green plants') comprise the Chlorophyta (freshwater and marine algae) and the Streptophytes, which include the Charophyte group of green algae and the land plants (Lewis and McCourt 2004). The Charophytes, which reside in a range of freshwater and subaerial habitats, are the closest living relatives of land plants (Kenrick and Crane 1997; Leliaert et al. 2012). There are six distinct classes within the Charophytes; Mesostigmatophyceae, Chlorokybophyceae, Klebsormidiaceae, Coleochaetophyceae, 
Charophyceae and the Zygnematophyceae (McCourt et al. 2004). Some studies have positioned Charophyceae as the closest living relative of land plants, a reasonable assumption considering the morphological complexity within the group (Karol et al. 2001; Turmel et al. 2003). However, other studies have suggested that the Coleochaetophyceae or a combined Coleochaetophyceae/Zygnematophyceae clade represent the closest relatives of land plants (Finet et al. 2010; Wodniok et al. 2011). More recent and well supported phylogenetic studies place the Zygnematophyceae as the closest living relative to land plants (Fig. 1; Puttick et al. 2018; Timme et al. 2012; Wickett et al. 2014). As streptophyte lineages diverge, their morphological diversity becomes increasingly complex, from organisms that are unicellular to those that are multicellular non-branching to multicellular branching to those with complex multicellular organisation and subsequently those that exhibit 3D growth. This review summarizes the evolving morphological complexity within the Streptophytes, from early divergent Charophytes to the earliest divergent land plants.

\section{The early divergent charophytes}

The Mesostigmatophyceae and Chlorokybophyceae are widely accepted to represent the earliest diverging streptaphyte lineages, followed by the divergence of the Klebsormidiaceae (Lemieux et al. 2007; Rodriguez-Ezpeleta et al. 2006; Timme et al. 2012). The early divergent Charophytes divide by a distinct mechanism of cell division, which involves the formation of a cleave furrow (Leliaert et al. 2012). The Mesostigmatophyceae are considered the most basal group within the Charophytes. The representative species Mesostigma viride is defined as a scaly green unicellular flagellate, which has three layers of ornate scales in the absence of a cell wall (Fig. 2a). These unicells are typically asymmetrically shaped, bear two flagella and occupy freshwater habitats (Marin and Melkonian 1999; Rogers et al. 1981). The Chlorokybophyceae are represented by the sole species Chlorokybus atmophyticus, which forms packets of non-motile cells that reproduce asexually (Fig. 2b). Chlorokybus atmophyticus occupies subaerial habitats and has

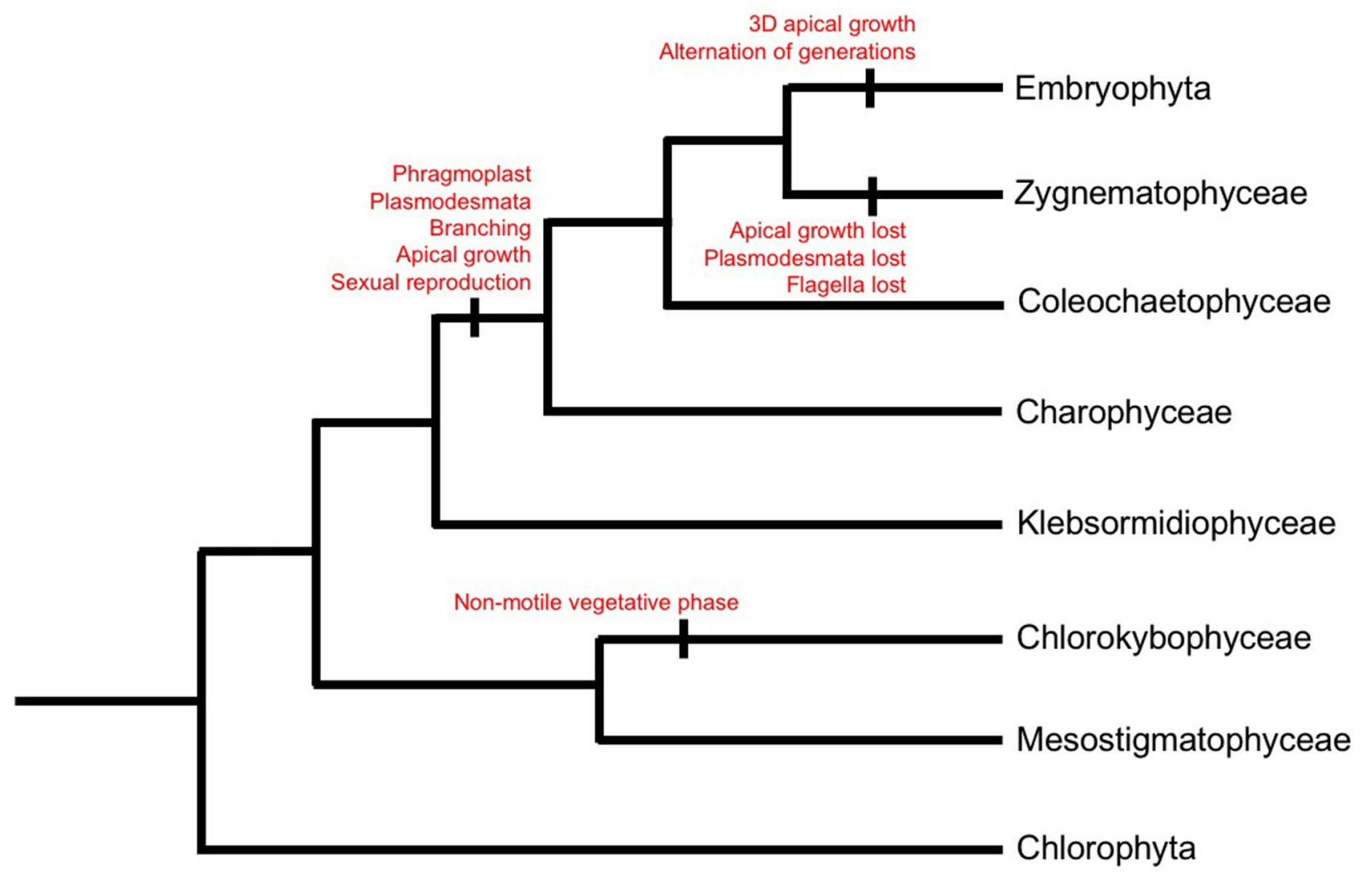

Fig. 1 Evolution of the Streptophytes. Cladogram illustrating the evolution of the Charophytes and land plants ('the Streptophytes'). The cladogram topology was selected based on recent phylogenetic studies that place the Zygnematophyceae as the closest living relative to land plants (Puttick et al. 2018; Timme et al. 2012; Wickett et al. 2014). The gains and losses of important morphological characteristics within the lineages have been indicated. 

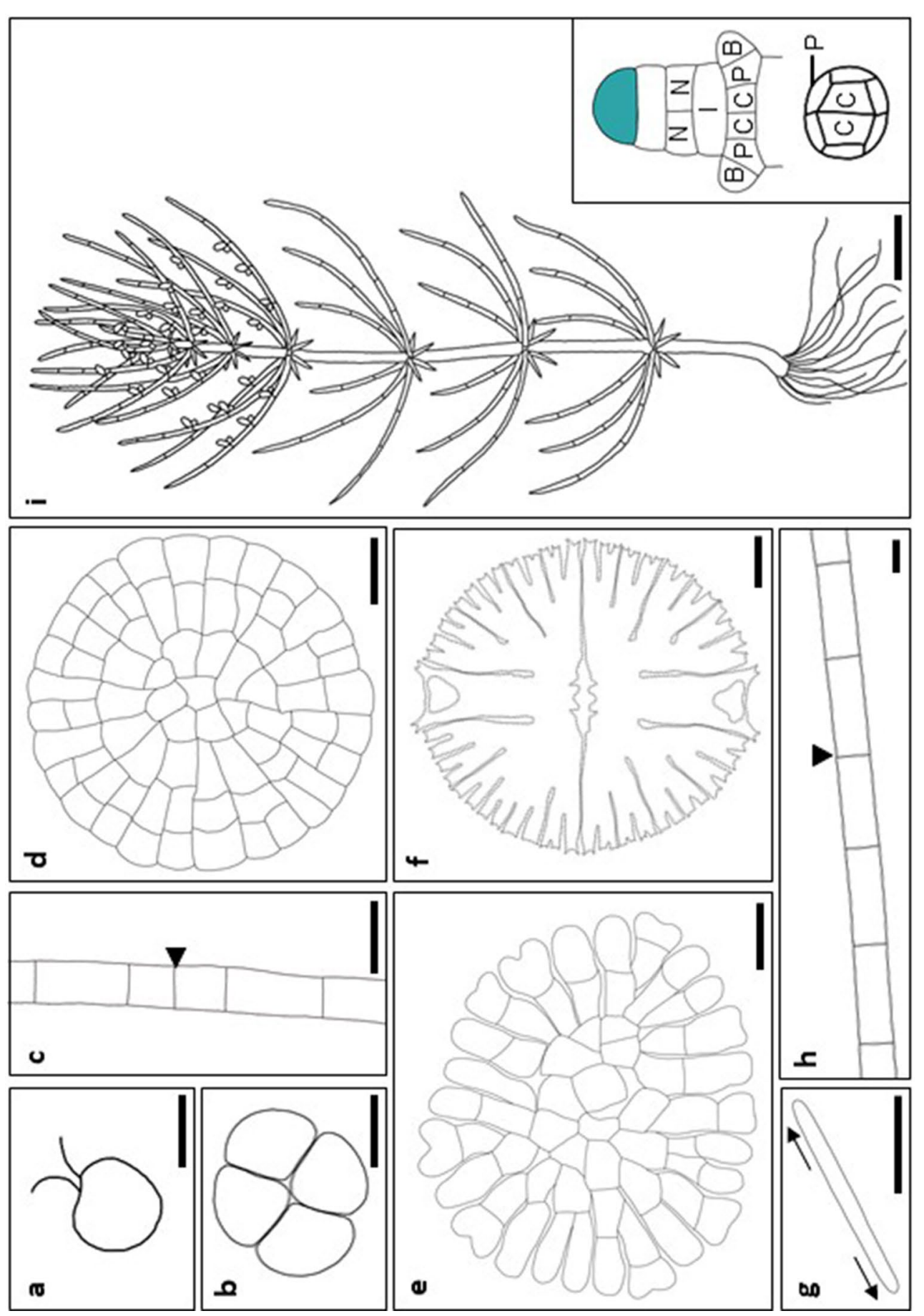

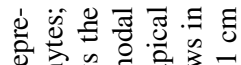

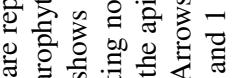

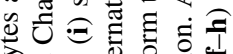

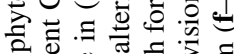

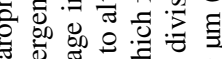

छ

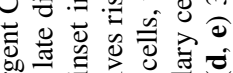

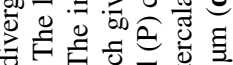

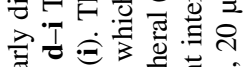

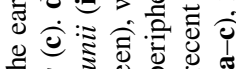

政券

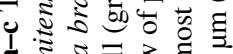

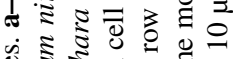

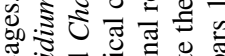

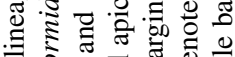

๑ั

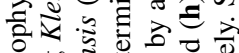

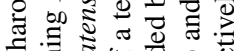

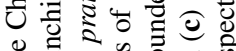

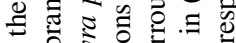

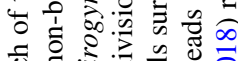

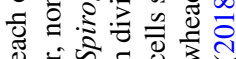

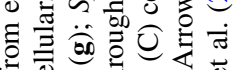

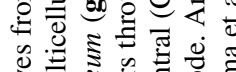

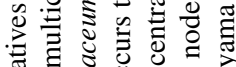

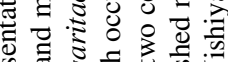

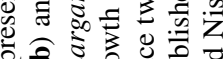

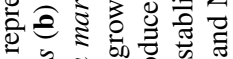

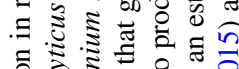

ㄷำ

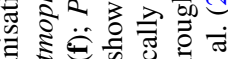

䓪 है

施

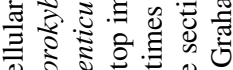

\% す

을

है बิ

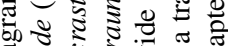

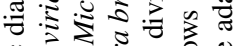

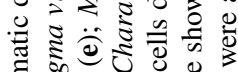

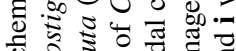

造

sं

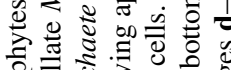

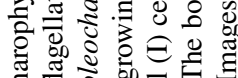

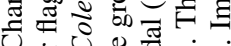

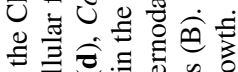

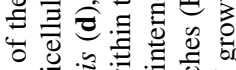

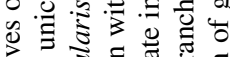

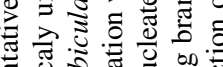

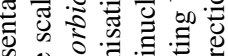

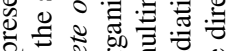

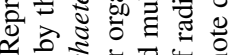

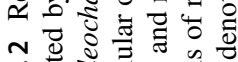

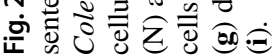


the capacity to survive desiccation, freezing and UV exposure (Lokhurst et al. 1988; Rogers et al. 1980). The Klebsormidiaceae are composed of multicellular and non-branching filaments with cell division taking place throughout the length of the filament, and not at apices (Fig. 2c; Pierangelini et al. 2017). Representatives of the Klebsormidiaceae can survive in water as well as subaerial conditions and are both desiccation and freezing tolerant (Elster et al. 2008; Morison and Sheath 1985; Nagao et al. 2008). The genome sequence of Klebsormidium nitens (formerly identified as Klebsormidium flaccidum) revealed that the Klebsormidiaceae produce phytohormones and may respond to radiation exposure using similar mechanisms to those found in land plants (Hori et al. 2014).

\section{The late divergent charophytes}

The Coleochaetophyceae, Charophyceae and Zygnematophyceae share a number of key characteristics with land plants, such as the formation of complex cell walls, plasmodesmata for intercellular communication, and the ability to divide asymmetrically (Cook et al. 1997; Nishiyama et al. 2018; Sorensen et al. 2011; Umen 2014). The late divergent Charophytes and the land plants also established a new mechanism of cell division, which involved the formation of a phragmoplast (Cook et al. 1997). For this reason, the Coleochaetophyceae, Charophyceae, Zygnematophyceae and the land plants collectively form the 'Phragmoplastophyta' (Nishiyama et al. 2018).

The Coleochaetophyceae form branching filaments, in which apical cells with two cutting faces give rise to twodimensional (2D) mats. Coleochaete orbicularis appears as unistratose discs, which grow by means of a marginal meristem. Cells within the thallus are generally constrained by neighbouring cells but peripheral cells are capable of polar expansion and grow away from the centre of the thallus. Peripheral cells can divide precisely in either anticlinal or periclinal directions to allow radial and circumferential thallus growth (Fig. 2d; Barlow et al. 2002; Brown et al. 1994; Cook 2004; Doty et al. 2014; Marchant and PickettHeaps 1973). Coleochaete soluta develops in a similar manner, but there are some important distinctions. Peripheral cells are lobed, and discs comprise laterally adherent branched filaments that are contained within a significant layer of mucilage (Fig. 2e; Doty et al. 2014). Conversely, Coleochaete pulvinata comprises a $2 \mathrm{D}$ branching filamentous thallus, which can differentiate into both prostrate and upright forms, all enclosed within extensive mucilage. Apical growth is exhibited in branches of the upright form, and these are derived from outgrowths of the prostrate form. The Coleochaetophyceae have true multicellular organisation, in which plasmodesmata facilitate intercellular communication. They are also capable of sexual reproduction, in which male (antheridia) and female (oogonia) organs are present although organised differently in discoid (C. orbicularis, $C$. soluta) versus cushioned (C. pulvinate) forms (Delwiche et al. 2002; Graham et al. 2012; Timme and Delwiche 2010).

The Zygnematophyceae, also known as the 'conjugating green algae', represent the most species-rich and morphologically diverse streptophyte lineage. Members of this group lack flagellated cells and instead reproduce by means of conjugation (Wodniok et al. 2011). The Zygnematophyceae are represented by both unicellular and multicellular filamentous forms. Species within the Zygnematophyceae appear to have evolved to lose morphological complexity because they lack both apical growth and plasmodesmata (Fig. 1). The unicellular desmids Microasterias denticulata (Holzinger and Lutz-Meindl 2002; Meindl et al. 1994; Neustupa and Stastny 2018) and Penium margaritaceum (Domozych 2014; Ochs et al. 2014; Sorensen et al. 2014) have become experimental systems for studies of cell biology and plant cell morphogenesis through ease of their microscopic analysis. Microasterias denticulata is highly dissected, bilaterally symmetrical and can reproduce asexually by binary fission (Fig. 2f; Graham et al. 2015). In P. margaritaceum, the deposition of new cell wall material at the centre of the cell ('isthmus') facilitates bidirectional cell expansion (Fig. 2g). The isthmus also marks the site of cytokinesis, which is facilitated by microtubules (Ochs et al. 2014). The unbranched multicellular and filamentous alga Spirogyra pratensis grows by intercalary cell division (Fig. 2h). Filament fragmentation can start growth of new filaments, which can stagnate in freshwater and produce algal blooms very rapidly (Ju et al. 2015; Stancheva et al. 2013).

The Charophyceae comprise large morphologically complex macroalgae, which bear a close resemblance to land plants. The emerging model species Chara braunii comprises a central stem, which grows from a terminal apical cell, with branchlets that radiate from axial nodes. Each branchlet within a whorl is derived from a nodal initial and each whorl is separated by an elongated multinucleate internodal cell. Nodal and internodal cells are alternately derived from the apical cell, allowing branchlets to emanate at regular intervals along the stem. Once formed, the resulting branchlets are able to extend (1D growth) and branch (2D growth). C. braunii is monoecious and bears both the male (antheridia) and female (oogonia) gametangia on the branchlet nodes (Fig. 2i; Nishiyama et al. 2018).

\section{The early land pioneers}

The earliest pioneers on land were the bryophytes, which include the mosses, liverworts and hornworts. The phylogenetic relationships among the bryophytes and the vascular plants remains a widely debated topic. However, there remains significant support for a monophyletic origin of the 
bryophytes, and a relationship between the hornworts and a setaphyte clade comprising the mosses and liverworts (de Sousa et al. 2019; Puttick et al. 2018). A unifying feature of the bryophytes is a dominant haploid gametophyte stage of the life cycle, and a diploid sporophyte stage that is both multicellular and nurtured by the gametophyte (Sakakibara et al. 2008).

The life cycle of the moss Physcomitrella patens begins with spore germination and the formation of a chloronemal apical cell, which can divide successively in 1D to enable filament extension. Chloronemal apical cells at growing tips can continue to divide to self-renew or can choose to differentiate into caulonemal apical cells, which can divide to produce filaments of caulonemal cells. Cells that are not immediately adjacent to apical cells can cleave in two planes (2D) to form side branches (a chloronemal apical cell or a caulonemal apical cell) or a gametophore apical cell. Gametophore apical cells divide obliquely twice, and an additional two rotating cell divisions establish a tetrahedral apical cell with three cutting faces, thus establishing three-dimensional (3D) growth (Fig. 3a-e). Self-renewal and differentiation processes produce a leafy gametophore composed of many phyllids spirally arranged around a stem. Successive anticlinal and periclinal divisions distal to growing tips allow phyllids to assume their final shape. Mature gametophores bear the reproductive organs antheridia and archegonia (Harrison et al. 2009).

The filamentous phase of the liverwort Marchantia polymorpha is more transient than that of $P$. patens. In sufficient light conditions, spore germination gives rise to sporelings that grow in an isotropic manner before establishing an apical cell. However, in low red-light conditions, sporelings can divide unidirectionally (1D) to form a polarised 'protonema-like' structure (Ishizaki et al. 2016; Nishihama et al. 2015). Cells of the sporelings then divide in a second plane to produce a branched, spherical thallus. A lenticular-shaped apical cell with two cutting faces is established, which subsequently divides to produce a thallus comprising a single cell layer (Shimamura 2016). The apical cell becomes incorporated into an apical notch and ultimately adopts a distinctive 'wedge-shaped' morphology with the capacity to divide in four planes (3D growth) and add cell layers to build a multistratose thallus that can anchor to substrata (Fig. 3f-i; Crandall-Stotler 1981; O’Hanlon 1926). Marchantia polymorpha can reproduce asexually by fragmentation, by producing gemmae in gemma cups ('splash cups'), or sexually by producing antheridia and archegonia on free-living dioecious plants (Miller 1964; Miller and Colaiace 1969).

\section{The brown algae}

The brown algae are a group of multicellular marine algae that have evolved independently of land plants for more than one billion years. Yet brown algae and land plants share traits that are remarkable similar. These include apical growth, the formation of plasmodesmata for intercellular communication and the development of a multicellular sporophyte generation (Arun et al. 2013, 2019; Terauchi et al. 2015). Most notably, families within the Fucales exhibit 3D growth and produce apical cells with three cutting faces (Fig. 4). The Sargassum group has been rather comprehensively studied because members of this group can arrange organs radially around a central axis (Blomquist 1945; Fritsch 1945). In Sargassum muticum (and other species such as S. vulgare), an apical cell, which is contained within an apical pit filled with mucilage, divides from all three faces to produce promeristematic cells. These repeatedly divide to give rise to cells that make up the meristoderm, cortex and medulla layers of the alga body (Kaur 1999; Linardić and Braybrook 2017; Peaucelle and Couder 2016). Sargassum muticum comprises a root-like holdfast, which gives rise to the central axis (stipe). The stipe has a meristematic apex that produces hierarchically organised primary branches, each able to produce radially organised leaf-like blades, air bladders and reproductive receptacles from its own meristematic apex (Linardić and Braybrook 2017; Peaucelle and Couder 2016).

\section{Summary}

There are important morphological distinctions that distinguish the Charophytes from land plants. Most notably, Charophyte body plans are derived from growth in $1 \mathrm{D}$ or $2 \mathrm{D}$ and comprise filaments, mats and branches. However, land plants acquired apical cells that could cleave in three or more planes, enabling them to develop the morphological toolkit required to survive out of the water. $3 \mathrm{D}$ growth is thus an invariable and pivotal feature of all land plants. Intriguingly, $3 \mathrm{D}$ apical growth has also evolved within some species of brown algae, which have been evolving independently of the Streptophytes for over a billion years.

Open Access This article is licensed under a Creative Commons Attribution 4.0 International License, which permits use, sharing, adaptation, distribution and reproduction in any medium or format, as long as you give appropriate credit to the original author(s) and the source, provide a link to the Creative Commons licence, and indicate if changes were made. The images or other third party material in this article are included in the article's Creative Commons licence, unless indicated otherwise in a credit line to the material. If material is not included in the article's Creative Commons licence and your intended use is not permitted by statutory regulation or exceeds the permitted use, you will need to obtain permission directly from the copyright holder. To view a copy of this licence, visit http://creativecommons.org/licenses/by/4.0/. 


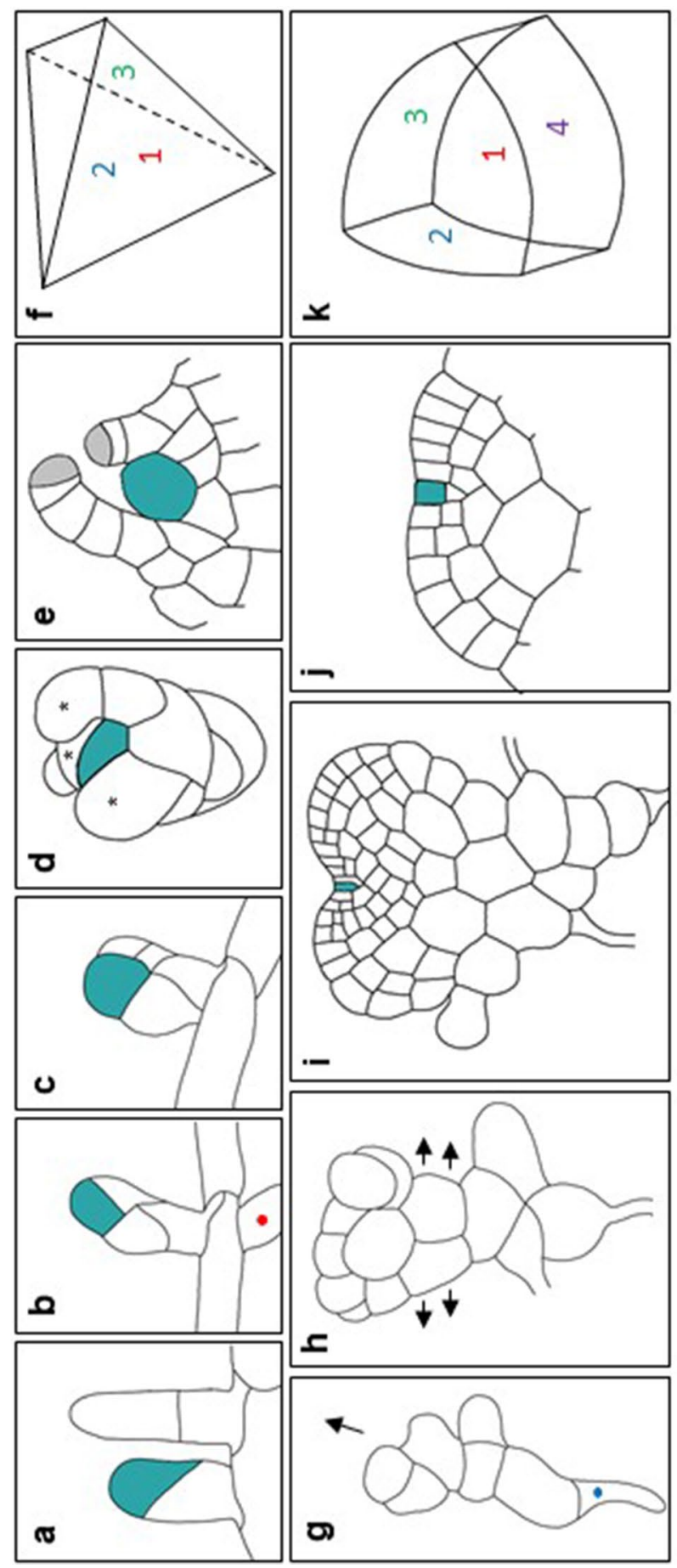

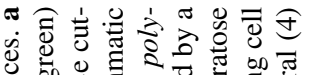

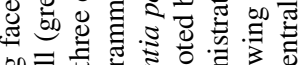

,

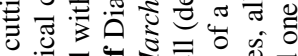

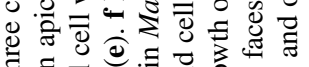

声 ส

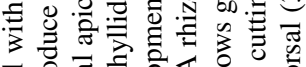

ষ

తึ

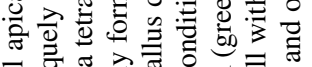

폅.

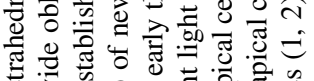

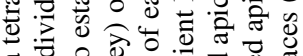

厅

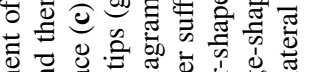

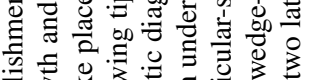

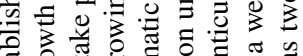

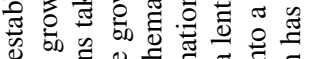

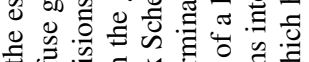

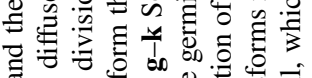

ऽ च

逑

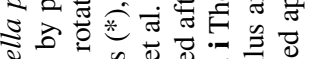

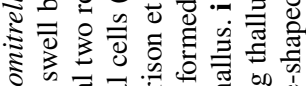

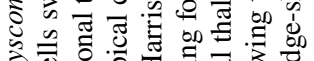

ई

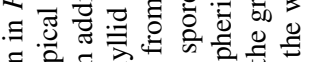

ฮี สิ

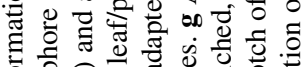

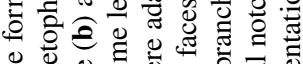

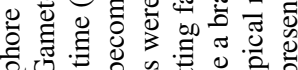

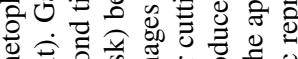

突

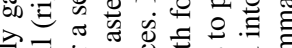

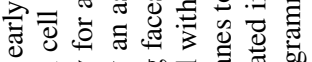

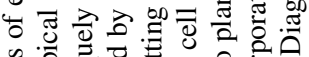

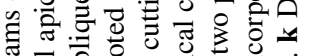

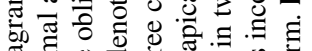

可

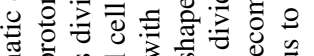

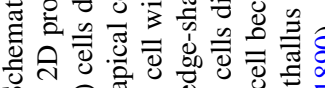
ช สิ สิ

๘

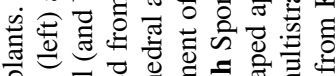

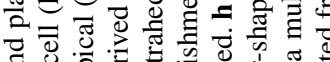

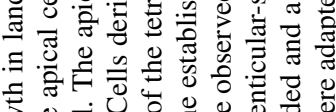

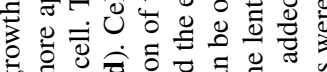

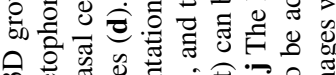

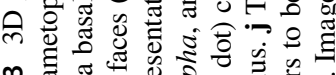

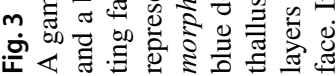




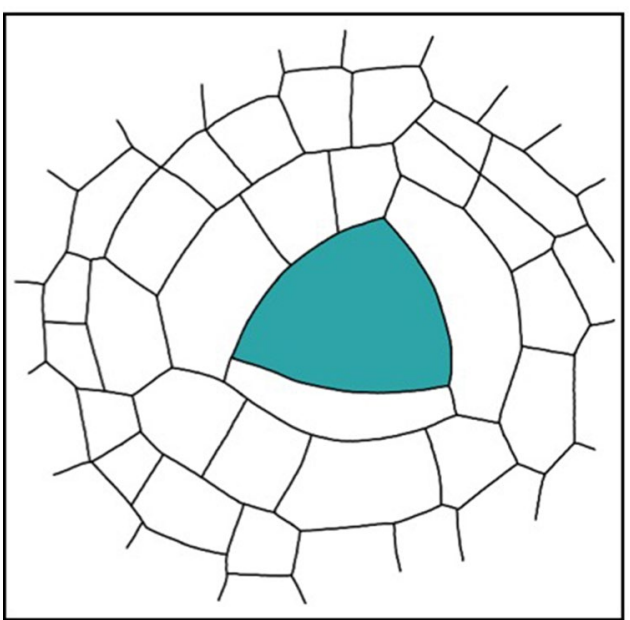

Fig. 4 3D growth in brown algae. Schematic diagram showing the apical cell (green) of the brown alga Turbinaria turbinata, which has three cutting faces. Image adapted from Blomquist (1945).

\section{References}

Arun A, Coelho SM, Peters AF et al (2019) Convergent recruitment of TALE homeodomain life cycle regulators to direct sporophyte development in land plants and brown algae. eLife 8:e43101. https ://doi.org/10.7554/eLife.43101

Arun A, Peters NT, Scornet D et al (2013) Non-cell autonomous regulation of life cycle transitions in the model brown alga Ectocarpus. New Phytol 197:503-510. https://doi.org/10.1111/nph.12007

Barlow PW, Brain P, Powers SJ (2002) Estimation of directional division frequencies in vascular cambium and in marginal meristematic cells of plants. Cell Prolif 35:49-68. https://doi.org/10. 1046/j.1365-2184.2002.00225.x

Blomquist HL (1945) Development of reproductive structures in the brown alga Turbinaria turbinata. Bot Gaz 106:290-304

Brown RC, Lemmon BE, Graham LE (1994) Morphogenetic plastid migration and microtubule arrays in mitosis and cytokinesis in the green alga Coleochaete orbicularis. Am J Bot 81:127-133. https://doi.org/10.1002/j.1537-2197.1994.tb15421.x

Cook ME (2004) Cytokinesis in Coleochaete orbicularis (Charophyceae): an ancestral mechanism inherited by plants. Am J Bot 91:313-320. https://doi.org/10.3732/ajb.91.3.313

Cook ME, Graham LE, Botha CEJ, Lavin CA (1997) Comparative ultrastructure of plasmodesmata of Chara and selected bryophytes: toward an elucidation of the evolutionary origin of plant plasmodesmata. Am J Bot 84:1169-1178. https://doi. org/10.2307/2446040

Crandall-Stotler B (1981) Morphology/anatomy of hepatics and anthocerotes. Adv Bryol 1:315-398

Delwiche CF, Karol KG, Cimino MT, Sytsma KJ (2002) Phylogeny of the genus Coleochaete (Coleochaetales, Charaphyta) and related taxa inferred by analysis of the chloroplast gene $r b c L 1$. J Phycol 38:394-403. https://doi.org/10.1046/j.1529-8817.2002.01174.x

Delwiche CF, Cooper ED (2015) The evolutionary origin of a terrestrial flora. Curr Biol 25:R899-R910. https://doi.org/10.1016/j. cub.2015.08.029

Domozych D (2014) Penium margaritaceum: a unicellular model organism for studying plant cell wall architecture and dynamics. Plants 3:543-558. https://doi.org/10.3390/plants3040543

Doty KF, Betzelberger AM, Kocot KM, Cook ME (2014) Immunofluorescence localization of the tubulin cytoskeleton during cell division and cell growth in members of the Coleochaetales (Streptophyta). J Phycol 50:624-639. https://doi.org/10.1111/jpy.12194

Elster J, Degma P, Kováčik L' et al (2008) Freezing and desiccation injury resistance in the filamentous green alga Klebsormidium from the Antarctic. Arctic Slovakia Biologia 63:843-851. https ://doi.org/10.2478/s11756-008-0111-2

Finet C, Timme RE, Delwiche CF, Marlétaz F (2010) Multigene phylogeny of the green lineage reveals the origin and diversification of land plants. Curr Biol 20:2217-2222. https://doi.org/10.1016/j. cub.2010.11.035

Fritsch FE (1945) Observations on the anatomical structure of the Fucales. New Phytol 44:1-16

Graham LE, Arancibia-Avila P, Taylor WA et al (2012) Aeroterrestrial Coleochaete (Streptophyta, Coleochaetales) models early plant adaptation to land. Am J Bot 99:130-144. https://doi.org/10.3732/ ajb. 1100245

Graham LE, Graham JM, Wilcox LW, Cook ME (2015) Algae, 3rd ed. LJLM Press, San Francisco

Harrison CJ, Roeder AHK, Meyerowitz EM, Langdale JA (2009) Local cues and asymmetric cell divisions underpin body plan transitions in the moss Physcomitrella patens. Curr Biol 19:461-471. https://doi.org/10.1016/j.cub.2009.02.050

Holzinger A, Meindl U (2002) Kinesin-like proteins are involved in postmitotic nuclear migration of the unicellular green alga Micrasterias denticulata. Cell Biol Int 26:689-697. https://doi. org/10.1006/cbir.2002.0920

Hori K, Maruyama F, Fujisawa T et al (2014) Klebsormidium flaccidum genome reveals primary factors for plant terrestrial adaptation. Nat Commun 5:3978. https://doi.org/10.1038/ncomms4978

Ishizaki K, Nishihama R, Yamato KT et al (2016) Molecular genetic tools and techniques for Marchantia polymorpha research. Plant Cell Physiol 57:262-270. https://doi.org/10.1093/pcp/pcv097

Ju C, Van de Poel B, Cooper ED et al (2015) Conservation of ethylene as a plant hormone over 450 million years of evolution. Nat Plants 1:14004. https://doi.org/10.1038/nplants.2014.4

Karol KG, McCourt RM, Cimino MT, Delwiche CF (2001) The closest living relatives of land plants. Science 294:2351-2353. https ://doi.org/10.1126/science.1065156

Kaur I (1999) Apical meristem of Sargassum vulgare C. Agardh (Phaeophyta, Fucales). Algae 14:37-42

Kenrick P, Crane PR (1997) The origin and early evolution of plants on land. Nature 389:33-39. https://doi.org/10.1038/37918

Kny L (1890) Bau und entwickelung von Marchantia polymorpha. In: von Wiegandt V (ed) Botanische Wandtafeln Mit Erläuterndem

Leliaert F, Smith DR, Moreau H et al (2012) Phylogeny and molecular evolution of the green algae. Crit Rev Plant Sci 31:1-46. https://doi.org/10.1080/07352689.2011.615705

Lemieux C, Otis C, Turmel M (2007) A clade uniting the green algae Mesostigma viride and Chlorokybus atmophyticus represents the deepest branch of the Streptophyta in chloroplast genome-based phylogenies. BMC Biol 5:2. https://doi. org/10.1186/1741-7007-5-2

Lewis LA, McCourt RM (2004) Green algae and the origin of land plants. Am J Bot 91:1535-1556. https://doi.org/10.3732/ ajb.91.10.1535

Linardić M, Braybrook SA (2017) Towards an understanding of spiral patterning in the Sargassum muticum shoot apex. Sci Rep 7:13887. https://doi.org/10.1038/s41598-017-13767-5

Lokhorst GM, Sluiman HJ, Star W (1988) The ultrastructure of mitosis and cytokinesis in the sarcinoid Chlorokybus atmophyticus (Chlorophyta, Charophyceae) revealed by rapid freeze fixation and freeze substitution. J Phycol 24:237-248. https://doi. org/10.1111/j.1529-8817.1988.tb04239.x

Marchant HJ, Pickett-Heaps JD (1973) Mitosis and cytokinesis in Coleochaete scutata. J Phycol 9:461-471. https://doi. org/10.1111/j.1529-8817.1973.tb04122.x 
Marin B, Melkonian M (1999) Mesostigmatophyceae, a new class of Streptophyte green algae revealed by SSU rRNA sequence comparisons. Protist 150:399-417. https://doi.org/10.1016/ S1434-4610(99)70041-6

McCourt RM, Delwiche CF, Karol KG (2004) Charophyte algae and land plant origins. Trends Ecol Evol 19:661-666. https://doi. org/10.1016/j.tree.2004.09.013

Meindl U, Zhang D, Hepler PK (1994) Actin microfilaments are associated with the migrating nucleus and the cell cortex in the green alga Micrasterias. Studies on living cells. J Cell Sci 107:1929-1934

Miller MW (1964) A technique for isolating and culturing gemmae of Marchantia polymorpha L. under aseptic conditions. Bryologist 67:317. https://doi.org/10.2307/3240894

Miller MW, Colaiace J (1969) The induction of sexual reproductive structures of Marchantia polymorpha grown under aseptic culture conditions. Bryologist 72:45. https://doi.org/10.2307/3241355

Minami A, Nagao M, Arakawa K et al (2003) Abscisic acid-induced freezing tolerance in the mossPhyscomitrella patens is accompanied by increased expression of stress-related genes. J Plant Physiol 160:475-483. https://doi.org/10.1078/0176-1617-00888

Morison MO, Sheath RG (1985) Responses to desiccation stress by Klebsormidium rivulare (Ulotrichales, Chlorophyta) from a Rhode Island stream. Phycologia 24:129-145. https://doi.org/10.2216/ i0031-8884-24-2-129.1

Nago M, Matsui K, Uemura M (2008) Klebsormidium flaccidum, a charophycean green alga, exhibits cold acclimation that is closely associated with compatible solute accumulation and ultrastructural changes. Plant Cell Environ 31:872-885. https://doi.org/10. $1111 / \mathrm{j} .1365-3040.2008 .01804 . x$

Neustupa J, Stastny J (2018) Symmetry breaking of the cellular lobes closely relates to phylogenetic structure within green microalgae of the Micrasterias lineage (Zygnematophyceae). PeerJ 6:e6098. https://doi.org/10.7717/peerj.6098

Nishihama R, Ishizaki K, Hosaka M et al (2015) Phytochrome-mediated regulation of cell division and growth during regeneration and sporeling development in the liverwort Marchantia polymorpha. J Plant Res 128:407-421. https://doi.org/10.1007/s1026 5-015-0724-9

Nishiyama T, Sakayama H, de Vries J et al (2018) The Chara genome: secondary complexity and implications for plant terrestrialization. Cell 174:448-464.e24. https://doi.org/10.1016/j.cell.2018.06.033

O'Hanlon ME (1926) Germination of the spores and early stages in the development of the gametophyte of Marchantia polymorpha. Bot Gaz 82:215-222

Ochs J, LaRue T, Tinaz B et al (2014) The cortical cytoskeletal network and cell-wall dynamics in the unicellular charophycean green alga Penium margaritaceum. Ann Bot 114:1237-1249. https://doi. org/10.1093/aob/mcu013

Peaucelle A, Couder Y (2016) Fibonacci spirals in a brown alga [Sargassum muticum (Yendo) Fensholt] and in a land plant [Arabidopsis thaliana (L.) Heynh.]: a case of morphogenetic convergence. Acta Soc Bot Pol 85:3526. https://doi.org/10.5586/asbp.3526

Pierangelini M, Ryšánek D, Lang I et al (2017) Terrestrial adaptation of green algae Klebsormidium and Zygnema (Charophyta) involves diversity in photosynthetic traits but not in $\mathrm{CO} 2$ acquisition. Planta 246:971-986. https://doi.org/10.1007/s00425-017-2741-5

Puttick MN, Morris JL, Williams TA et al (2018) The interrelationships of land plants and the nature of the ancestral embryophyte. Curr Biol 28:733-745.e2. https://doi.org/10.1016/j.cub.2018.01.063

Rodriguez-Ezpeleta N, Philippe H, Brinkmann H et al (2006) Phylogenetic analyses of nuclear, mitochondrial, and plastid multigene data sets support the placement of Mesostigma in the Streptophyta. Mol Biol Evol 24:723-731. https://doi.org/10.1093/molbev/msl200

Rogers CE, Domozych DS, Stewart KD, Mattox KR (1981) The flagellar apparatus of Mesostigma viride (Prasinophyceae): multilayered structures in a scaly green flagellate. Plant Syst Evol 138:247-258. https://doi.org/10.1007/BF00985188

Rogers CE, Mattox KR, Stewart KD (1980) The zoospore of Chlorokybus atmophyticus, a charophyte with sarcinoid growth habit. Am J Bot 67:774. https://doi.org/10.2307/2442669

Sakakibara K, Nishiyama T, Deguchi H, Hasebe M (2008) Class 1 KNOX genes are not involved in shoot development in the moss Physcomitrella patens but do function in sporophyte development. Evol Dev 10:555-566. https://doi.org/10.1111/j.1525-142X.2008.00271.x

Shimamura M (2016) Marchantia polymorpha: taxonomy, phylogeny and morphology of a model system. Plant Cell Physiol 57:230 256. https://doi.org/10.1093/pcp/pcv192

Sørensen I, Fei Z, Andreas A et al (2014) Stable transformation and reverse genetic analysis of Penium margaritaceum: a platform for studies of charophyte green algae, the immediate ancestors of land plants. Plant J 77:339-351. https://doi.org/10.1111/tpj.12375

Sørensen I, Pettolino FA, Bacic A et al (2011) The charophycean green algae provide insights into the early origins of plant cell walls. Plant J 68:201-211. https://doi.org/10.1111/j.1365313X.2011.04686.x

Sousa F, Foster PG, Donoghue PCJ et al (2019) Nuclear protein phylogenies support the monophyly of the three bryophyte groups (Bryophyta Schimp.). New Phytol 222:565-575. https://doi. org/10.1111/nph.15587

Stancheva R, Hall JD, McCourt RM, Sheath RG (2013) Identity and phylogenetic placement of Spirogyra species (Zygnematophyceae, Charophyta) from California streams and elsewhere 1. J Phycol 49:588-607. https://doi.org/10.1111/jpy.12070

Stevenson SR, Kamisugi Y, Trinh CH et al (2016) Genetic analysis of Physcomitrella patens identifies ABSCISIC ACID NONRESPONSIVE, a regulator of ABA responses unique to basal land plants and required for desiccation tolerance. Plant Cell 28:1310-1327. https://doi.org/10.1105/tpc.16.00091

Terauchi M, Nagasato C, Motomura T (2015) Plasmodesmata of brown algae. J Plant Res 128:7-15. https://doi.org/10.1007/s1026 5-014-0677-4

Timme RE, Delwiche CF (2010) Uncovering the evolutionary origin of plant molecular processes: comparison of Coleochaete (Coleochaetales) and Spirogyra (Zygnematales) transcriptomes. BMC Plant Biol 10:96. https://doi.org/10.1186/1471-2229-10-96

Timme RE, Bachvaroff TR, Delwiche CF (2012) Broad phylogenomic sampling and the sister lineage of land plants. PLoS One 7:e29696. https://doi.org/10.1371/journal.pone.0029696

Turmel M, Otis C, Lemieux C (2003) The mitochondrial genome of Chara vulgaris: insights into the mitochondrial DNA architecture of the last common ancestor of green algae and land plants. Plant Cell 15:1888-1903. https://doi.org/10.1105/tpc.013169

Umen JG (2014) Green algae and the origins of multicellularity in the plant kingdom. Cold Spring Harbor Perspect Biol 6:a016170a016170. https://doi.org/10.1101/cshperspect.a016170

Wickett NJ, Mirarab S, Nguyen N et al (2014) Phylotranscriptomic analysis of the origin and early diversification of land plants. Proc Natl Acad Sci 111:E4859-E4868. https://doi.org/10.1073/ pnas. 1323926111

Wodniok S, Brinkmann H, Glöckner G et al (2011) Origin of land plants: Do conjugating green algae hold the key? BMC Evol Biol 11:104. https://doi.org/10.1186/1471-2148-11-104

Wolf L, Rizzini L, Stracke R et al (2010) The molecular and physiological responses of Physcomitrella patens to Ultraviolet-B Radiation. Plant Physiol 153:1123-1134. https://doi.org/10.1104/ pp. 110.154658

Publisher's Note Springer Nature remains neutral with regard to jurisdictional claims in published maps and institutional affiliations. 